\title{
Evaluation of Heavy Metals Contamination in Agricultural Soils
}

\section{Jyoti Rani}

Deenbandhu Chhotu Ram University of Science and Technology, murthal

Sudesh Chaudhary ( $\nabla$ sudesh_choudhary@yahoo.com )

DCR University of Science and Technology Murthal https://orcid.org/0000-0002-3648-6626

Tripti Agarwal

National institute of Food Technology Entrepreneurship and management, sonepat

\section{Research}

Keywords: Contamination factor (CF), Enrichment factor (EF), National capital region (NCR), potential ecological risk index (PERI), principal component analysis (PCA)

Posted Date: March 26th, 2021

DOI: https://doi.org/10.21203/rs.3.rs-327423/v1

License: (c) (i) This work is licensed under a Creative Commons Attribution 4.0 International License. Read Full License 


\section{Abstract}

The present study was conducted to assess heavy metals contamination in agricultural soils in the National Capital Region, Delhi. A total of 84 soil samples were collected from selected agricultural areas located near industries, national highways, state highways, Yamuna floodplain, residential complexes, and wastewater irrigated soils. Heavy metal concentrations ( $\mathrm{Al}, \mathrm{Cd}, \mathrm{Co}, \mathrm{Cr}, \mathrm{Cu}, \mathrm{Fe}, \mathrm{Mn}, \mathrm{Ni}, \mathrm{Pb}$, and $\mathrm{Zn}$ ), $\mathrm{pH}$, and organic carbon (\%) were analyzed in the collected soil samples. The average value of $\mathrm{pH}$ and organic carbon in the soil samples collected were $7.79 \pm 0.49$ and $0.53 \pm 0.17$ percent. Average concentrations of heavy metals in soils were found to be in the order of $\mathrm{Fe}>\mathrm{Al}>\mathrm{Mn}>\mathrm{Zn}>\mathrm{Ni}>\mathrm{Cr}>\mathrm{Cu}>\mathrm{Pb}>\mathrm{Co}>\mathrm{Cd}$ with value as $14916.92 \mathrm{mg} \mathrm{kg}-1,13538.87 \mathrm{mg} \mathrm{kg}-1,277.16$

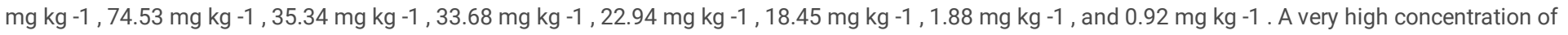
$\mathrm{Fe}$ (6640.09-32650.23 mg kg -1 ), Al (5631-27209.99 mg kg -1), Mn (73.8-735.72 mg kg -1 ), Zn (16.45-221.88 mg kg -1 ), Ni (7.63-192.63 mg kg -1 ), and Cr (9.65-127.21 mg kg -1) were recorded in agricultural soil samples. The average concentrations of $\mathrm{Mn}, \mathrm{Ni}$, and $\mathrm{Zn}$ in the soil samples were several times higher than their concentration in Indian natural background soils. A significant potential ecological risk has been noticed in nearly all the agricultural soil samples except for the samples collected nearby residential areas. The contamination factor has shown that most of the soil samples were moderately contaminated with $\mathrm{Mn}, \mathrm{Ni}, \mathrm{Fe}$, and $\mathrm{Cr}$ and some soil samples were considerably to strongly contaminated with $\mathrm{Cd}, \mathrm{Zn}, \mathrm{Pb}$, and Ni. Wastewater irrigated soils showed a moderate to a strong degree of accumulation of heavy metals ( $\mathrm{Cd}, \mathrm{Ni}$, and $\mathrm{Zn})$.

\section{Introduction}

Rapid industrialization, population explosion, and unregulated usage of natural resources have resulted in increased levels of all kinds of pollution in recent decades. As there is no boundary line of the environment, pollutants pass from one medium to another. Lead emitted into the atmosphere by leaded petrol had left its residues on plants, soil, and water [1]. The use of wastewater for irrigation and the application of sewage sludge as fertilizer in agricultural fields have resulted in increased concentrations of heavy metals in the soils. Illegal discharge of the wastewater into natural water bodies and soil ecosystems is also one of the contributing factors to the high concentrations of heavy metals in agricultural soils to a large extent [2]. Heavy metals are also entering agricultural soils through industrial solid waste discharge on land [3]. Agricultural activities (pesticides and fertilizers spray) are contributing heavy metals in agricultural soils. Soil is an important natural resource and serves as the basis for food production. It acts as a filter to remove pollutants from the water, which infiltrates down into the underground reservoirs. Soils polluted with heavy metals can result in groundwater contamination[4]. The vegetables cultivated in soil contaminated with heavy metals have shown accumulation of the metals in their edible and non-edible parts [5]. Although heavy metals (Fe, $\mathrm{Zn}, \mathrm{Ni}, \mathrm{Co}$, and $\mathrm{Cu}$ ) are required for plant growth, yet they may prove toxic to plants if they exceed certain threshold limits [6]. Heavy metals are non-biodegradable, mutagenic, carcinogenic and, accumulate at every trophic level through the food chain [7]. Excessive amounts of heavy metals in agricultural soils also lead to loss of crop quality and consequently adversely affect the health of consumers [8]. Dissolved and exchangeable forms of heavy metals are available for plant uptake [9]. Soil factors like $\mathrm{pH}$, organic matter, cation exchange capacity, soil texture, etc. regulate the mobility and availability of metals for plants [10]. Vegetables are an integral part of the human diet and are consumed by all. They are cash crops that require a short period of time to grow, and the concentration of the pollutants in them can vary over time. Heavy metals such as $\mathrm{Pb}$ and $\mathrm{Cd}$ have harmful effects on the nervous system and kidneys in humans [11]. Several studies have reported the presence of heavy metals in soils, but limited literature has been found regarding the evaluation of heavy metals in agricultural soils in the national capital region (NCR), India. In the present study, soil samples from vegetable cultivating areas of NCR were evaluated for heavy metals (Al, Cd, Co, Cr, $\mathrm{Cu}, \mathrm{Fe}, \mathrm{Mn}, \mathrm{Ni}, \mathrm{Pb}$, and $\mathrm{Zn}$ ) contamination.

\section{Materials And Methods}

\subsection{Study area}

India's National capital region (NCR) is the second-largest urban agglomeration in the world. Haryana contributes 48.93 percent (28,545 Km²) area of the NCR $\left(58,332 \mathrm{Km}^{2}\right)$ with 13 districts [12]. Industrialization in the NCR part constituted of Haryana is growing at a rapid pace. The different types of industries located in the area include metal and mineral-based, agro-based, electrical machinery, engineering units, repair and servicing, textile, auto parts, rubber, plastic, petro based motorcycle parts, diesel engines, etc. [13]. The region has a tropical climate and lies in the green revolution belt of the country. Four districts (Panipat, Sonipat, Gurugram, and Faridabad) of the NCR region have been selected for the present study. Horticulture is done on nearly 28.36 percent of the study area. The study area is having more than 60 percent industries of Haryana. The emission from these industries can contribute to a significant amount of heavy metals pollution in the surrounding area. Therefore, there is a need to assess the impact of industrialization in the area. Thus, considering the above point, the heavy metals concentration in agricultural soil samples was assessed in the present study.

\subsection{Sample collection and preparation}

Soil samples were collected from various agricultural fields of the study areas from May 2017 to February 2018 are shown in figure 1 . A $10 x 10 x 15 \mathrm{~cm}$ monolith was dug for a soil sample collection from five different locations in a field [14].A total of 84 soil samples approximately $2 \mathrm{~kg}$ of soil in each were collected in zip-lock polybags. The soil samples were brought to the laboratory and air-dried. The dried samples were crushed and passed through a 2-mmmess sieve. All samples were stored at ambient temperature before analysis.

\subsection{Analysis}

The $\mathrm{pH}$ of the soil was determined in 1:2.5 soil: water suspension using a digital pH meter [15]. Soil organic carbon content was determined by Walkley Black wet oxidation method [16]. For heavy metals analysis, 1 gram of dried soil samples was digested at $80^{\circ} \mathrm{C}$ on a hot plate under a fume hood after adding $15 \mathrm{ml}$ of a tri-acid mixture $\left(\mathrm{HNO}_{3}, \mathrm{H}_{2} \mathrm{SO}_{4}\right.$, and $\mathrm{HClO}_{4}$ in 5:1:1 ratio) until a transparent solution was obtained [17]. After cooling, the final volume of the digested sample was made up to $50 \mathrm{~mL}$ with double distilled water, and the sample was filtered using the Whatman No. 42 filter paper for analysis of heavy metals. 
The concentrations of $\mathrm{Al}, \mathrm{Cd}, \mathrm{Co}, \mathrm{Cr}, \mathrm{Cu}, \mathrm{Fe}, \mathrm{Mn}, \mathrm{Ni}, \mathrm{Pb}$, and $\mathrm{Zn}$ in the digested soil samples were estimated by atomic absorption spectrophotometer (Lab India AAS 8000). The glassware used in experimentation was washed with a $10 \% \mathrm{HNO}_{3}$ solution and then with double distilled water (DDW). Analytical grade chemicals and reagents used were purchased from Merck Company, Germany.

\subsection{Quality Control}

The instrument was calibrated with a blank and reference standard of heavy metals solution of different concentrations ( $0.02-10 \mathrm{ppm})$ at standard conditions $\left(r^{2}=0.99\right)$. Blank and standard were run after every 10 samples on the instrument. For quality assurance, triplicate readings were taken for each sample.

\subsection{Assessment of pollution sources}

Contamination factor (CF), enrichment factor (EF), and coefficient of variance (CV) were applied for estimating the heavy metal pollution levels in agricultural soil samples in the present study.

\subsubsection{Contamination factor (CF)}

The Contamination factor is defined as the ratio of the metal content $(\mathrm{Ci})$ in the soil to the background value $(\mathrm{Cb})$ of that metal in the soil, and is calculated as follow:

$$
C F=(C
$$

The background concentrations adopted were given in the table 3. CF was divided into six classes as shown in table 1 [18].

\subsubsection{Enrichment factor (EF)}

EF is a very effective tool for elucidating potential pollution sources of heavy metals in agricultural soil samples. The EF values of metals in soil samples were calculated as given in equation (2).

$$
E F=\frac{\left(c_{i} / C_{F i}\right.}{\left(C_{i} / C_{F}\right.} \quad \text { Eq. }(2)
$$

Where $\mathrm{C}_{\mathrm{i}}$ is the metal concentration and $\mathrm{C}_{\mathrm{Fe}}$ is the concentration of the reference element $(\mathrm{Fe})$ in the sample and continental crust. Background values for $\mathrm{EF}$ calculation were taken the same as taken for Igeo calculation. An EF value of $0.5-1.5$ indicates that a metal derives primarily from crustal materials through natural weathering processes, while EF> 1.5 indicates that a significant portion of metal arises from non-crustal or anthropogenic processes [19].

\subsubsection{Coefficient of variation (CV)}

The coefficient of variation is used to explain the degree of human intervention. $\mathrm{CV}$ is directly proportional to human intervention i.e. the higher the range of human activities, the higher the coefficient of variation will be. It has been classified in to three categories: low variation (CV $<0.15)$, medium variation $(0.15<$ $\mathrm{CV}<0.36)$ and high variation $(\mathrm{CV}>0.36)$, and is calculated as given in equation $3[19]$.

CV

2.6 Assessment of soil contamination

The Potential Ecological Risk Index (PERI) was used as a method of assessing the pollution status of agricultural soils. Ecological risk assessment is a technique used to identify the environmental impacts of metals in soil on the organisms and is calculated using Equations (4 and 5). RI is the ecological risk index defined as the sum of the potential ecological risk index $\left(\mathrm{E}_{\mathrm{i}}\right)$ of various metals present in the soil [19].

$$
\begin{aligned}
& R I=\Sigma \\
& E_{i}=T_{i}(C
\end{aligned}
$$

$\mathrm{E}_{\mathrm{i}}$ is the potential ecological risk index of an individual metal, $\mathrm{T}_{\mathrm{i}}$ is the toxic response factor (i.e., $\mathrm{Cd}=30, \mathrm{~Pb}=\mathrm{Cu}=\mathrm{Ni}=5 ; \mathrm{Cr}=2$; and $\mathrm{Zn}=1$ ), $\mathrm{C}_{\mathrm{i}} \mathrm{is}$ the concentration of metal $\mathrm{i}$ in soil, $\mathrm{CO}$ is the background concentration, Classification of PERI has been given in table 2.

2.7 Statistical analysis 
The bivariate correlation analysis with the Pearson's correlation coefficient ( $r$ ) with a two-tailed significance level (P), principal component analysis (PCA), and hierarchical cluster analysis (CA) using a complete linkage method were applied using SPSS software package (version 22.0 ).

\section{Results And Discussion}

3.1 Physico-chemical analysis

The $\mathrm{pH}$ and organic carbon are very important parameters of soil fertility as they control the mobility of heavy metals in soils. In the present study, pH of the agricultural soils was found to be alkaline in nature with an average value of $7.79 \pm 0.49$. Generally, heavy metals have shown high solubility at low pH, so the alkaline $\mathrm{pH}$ in the present study is supposed to reduce the solubility of heavy metals in the soil [20]. Although this is not true in every case of metals, Cd can become bioavailable in alkaline soil in the presence of calcium and zinc, which desorb the metals from soil particles [21]. The values of pH reported here are in good agreement with the values of pH reported in the agricultural soil samples collected from Panipat in India and Iran [22] The average value of organic carbon (\%) was found to be $0.53 \pm 0.21$ percent. Poor soil organic carbon decreases the microbial diversity and biomass of soil by reducing nutrient mineralization [23]. Soil organic matter can bind with heavy metals and hence controls the availability of heavy metals to the plants [24].

3.2 Heavy metals concentrations in soil

Average concentrations of heavy metal in soil samples were found to be in the order of $\mathrm{Fe}>\mathrm{Al}>\mathrm{Mn}>\mathrm{Zn}>\mathrm{Ni}>\mathrm{Cr}>\mathrm{Cu}>\mathrm{Pb}>\mathrm{Co}>\mathrm{Cd}$. The results of the present study were compared with the background concentration of heavy metals ( $\mathrm{Fe}, \mathrm{Cu}, \mathrm{Co}, \mathrm{Mn}, \mathrm{Zn}, \mathrm{Ni}, \mathrm{Pb}$, and $\mathrm{Cr}$ ) in the Haryana Indo-Gangetic plain and, for $\mathrm{Al}$ and Cd world's average soil heavy metal concentration values were taken, as the values were unavailable for Indian agricultural soils (Table 3 ).

\subsubsection{Iron}

The concentrations of $\mathrm{Fe}$ in all agricultural soils were within the background limits of Indian agricultural soils except for one sample that was collected from Ganaur (Sonepat). The concentration of iron in the soil sample of Ganaur was $32650.23 \mathrm{mg} \mathrm{kg}^{-1}$, which was near the national highway national highway 1 . The high concentration of iron in the agricultural soils may be due to the steel fabrication and machinery manufacturing industries situated near highways. The high concentration of Fe in the soils may also be attributed to its relative abundance in the earth's crust or continuous use of inorganic fertilizers in agricultural fields [25]. The concentrations of Fe reported here are higher than the concentrations reported by Punetha and Tewari in agricultural soils of Morabadad district, India [26]. The Iron concentration in the soil samples collected from agricultural fields on the Yamuna floodplain area in Panipat was also in good agreement with the earlier study [27].

\subsubsection{Aluminium}

The aluminium concentration in all the soil samples was below the world's average background concentration of the metal. The maximum concentration of aluminium was reported as $27209.99 \mathrm{mg} \mathrm{kg}^{-1}$ from the agricultural soil sample collected near the national highway in Ganaur (Sonipat) which may be due to the presence of steel fabrication and machine manufacturing industries on highways. Aluminum phosphide is also a registered pesticide for agricultural use in India, which can be a potential source of aluminium in agricultural land [28].

\subsubsection{Manganese}

The average Mn concentration in all the agricultural soil samples was higher than the background concentration of Mn in Indian agricultural soils, except for the soil samples that were collected from the sites located near residential areas. Mn concentration was three times higher in the agricultural soils located near state highways. The high concentration of $\mathrm{Mn}$ in the soil sample collected near highways may be attributed to several industries located there, such as the steel industry, spring industry, non-woven bag-making machine industry, precast concrete structure, and machine parts. Combustion of fossil fuel also contributes $\mathrm{Mn}$ in the environment [29]. $\mathrm{Mn}$ is also used as a desulfurizing agent in the iron-making industry and as an alloying element in various alloys [30]. $\mathrm{Mn}$ is a constituent of a fungicide (Mancozeb) and MnSO4 is used as a fertilizer in agriculture [29]. The Mn concentrations reported here were higher than the concentrations observed in agricultural soils of Panipat [31] and Varanasi [32].

\subsubsection{Zinc}

All the soil samples were having high concentrations of Zn, especially the wastewater irrigated agricultural soils had shown Zn concentration nine times higher than its background value. The drain water used for irrigation in the study areas is receiving city sewage and wastewater from different industries. The other reason for the high concentration of $\mathrm{Zn}$ in agricultural soil samples could be the application of $\mathrm{Zn}$ sulfate fertilizers [25]. Zn concentrations reported here were higher than concentrations reported in previous studies [9, 33].

\subsubsection{Nickel}

$\mathrm{Ni} \mathrm{concentrations} \mathrm{in} \mathrm{most} \mathrm{of} \mathrm{the} \mathrm{agricultural} \mathrm{soils} \mathrm{were} \mathrm{higher} \mathrm{than} \mathrm{the} \mathrm{background} \mathrm{concentration} \mathrm{of} \mathrm{Ni} \mathrm{in} \mathrm{Indian} \mathrm{agricultural} \mathrm{soil.} \mathrm{This} \mathrm{may} \mathrm{be} \mathrm{due} \mathrm{to} \mathrm{the}$ application of fertilizer, use of sewage, and industrial wastewater for irrigation [34]. The concentration of Ni was $23.9 \mathrm{mg} \mathrm{kg}^{-1} \mathrm{in}$ agricultural fields near highways and $157.15 \mathrm{mg} \mathrm{kg}^{-1}$ in wastewater irrigated fields, and was more than the concentrations reported in India and the China [33, 35].

\subsubsection{Chromium}

A high concentration of $\mathrm{Cr}\left(127.21 \mathrm{mg} \mathrm{kg}^{-1}\right)$ was found in wastewater irrigated soil in Sonepat. The high concentration of Cr in WWI soil may be due to the dumping of waste by printing and chemical industries in the drain. The mean concentration of $\mathrm{Cr}$ in the agricultural soils in the present study was higher than 
the concentration of $\mathrm{Cr}$ in agricultural soils of India [36], and other studies from the world [15, 19].

\subsubsection{Copper}

Most of the agricultural soil samples were having Cu concentrations within the background value of Indian agricultural soil except, for the one site which was irrigated by wastewater. The presence of $\mathrm{Cu}$ in this area may be attributed to the use of Cu-containing fungicides (copper sulfate and copper oxychloride) and the irrigation by sewage. The concentration of $\mathrm{Cu}$ reported in the present study was several times higher than the concentrations reported in agricultural soils of Jagdalpur, Chhattisgarh State, India [38] and of Marrakech in Morocco [39].

\subsubsection{Lead}

Concentrations of lead in the soil samples collected from national highways and state highways were found to exceed the background concentration of $\mathrm{Pb}$ in Indian agricultural soils. The mean concentration of $\mathrm{Pb}$ was almost three times higher than its background concentration value in these areas, which is pointing towards the anthropogenic input of this metal along with its natural sources. The other sources of Pb may be different types of industry located near the national highways like automobiles, paint, metallurgical, and battery manufacturing industries [40]. Pb get volatilize under high temperature and can travel a long distance from the source to the sink point. $\mathrm{Pb}$ is also found in phosphate and superphosphate rocks and has a strong binding with organic matter, which reduces its mobility [41]. The concentration of $\mathrm{Pb}$ in our study was higher than the concentration reported in agricultural soils in the Huainan City of China [42] and Amritsar city of Punjab, India [43].

\subsubsection{Cadmium}

The average concentration of cadmium in the agricultural soils in the present study was higher than the world's average. The highest concentration was found in the soil samples collected from wastewater irrigated areas in Sonepat city. The high concentration of Cd in the soils was due to irrigation by a drain that receives water from printing, chemical industries along with city sewage. It has been reported in a previous study that sewage irrigation is responsible for Cd input in Indian soils [44]. Another potential source of $\mathrm{Cd}$ in agricultural soil may be the use of Cd- containing fertilizers in the fields [45]. The Cd concentration reported in this study was higher than the concentration reported in China $[33,46]$. The results reported here also showed similarities with the results reported from peri-urban Delhi [47], and Southwestern China [48].

\subsubsection{Cobalt}

The concentrations of Cobalt in all of the collected agricultural soil samples were below the background value of Co in Indian agricultural soils. The cobalt concentrations reported here are higher than the values reported in Varanasi [35].

\subsection{Heavy metals pollution assessment}

\subsubsection{Contamination factor}

The contamination factor for agricultural soil samples has been calculated and shown in figure 2 . All of the agricultural soil samples were found to be contaminated with the different types of heavy metals. The samples collected from industrial areas, state highways, and national highways were moderately to considerably contaminated with $\mathrm{Cd}, \mathrm{Pb}$, and $\mathrm{Zn}$, respectively. Soil samples collected from the Yamuna floodplain were moderately to considerably contaminated with $\mathrm{Cd}$ whereas, wastewater irrigated soil samples were highly contaminated with $\mathrm{Cd}$, Ni, and $\mathrm{Zn}$. Agricultural soil samples near residential areas were also moderately contaminated with $\mathrm{Zn}$ due to the application of zinc fertilizers.

\subsubsection{Enrichment factor}

Average, minimum, maximum, and standard deviation values of enrichment factors (EF) in the agricultural soil samples are shown in figure 3 . The mean EF values in the agricultural soil samples followed the decreasing order of $\mathrm{Zn}>\mathrm{Cd}>\mathrm{Pb}>\mathrm{Mn}>\mathrm{Ni}>$ with average values 7.94, 5.82, 3.27, 3.12, and 2.78 , respectively. Thus the agricultural soils in the study area are highly enriched with $\mathrm{Zn}$ and $\mathrm{Cd}$, while moderately enriched with $\mathrm{Pb}$, Mn, and $\mathrm{Ni}$. The high EF value for these metals indicates the anthropogenic input of these metals in agricultural soils. The agricultural soils of east China had also shown enrichment with $\mathrm{Cd}$, Pb, and Zn, which were mainly derived from anthropogenic sources [19].

\subsubsection{Coefficient of variation (CV)}

$\mathrm{CV}$ was found in the order of $\mathrm{Pb}>\mathrm{Ni}>\mathrm{Co}>\mathrm{Cu}>\mathrm{Cr}>\mathrm{Zn}>\mathrm{Mn}>\mathrm{Cd}>\mathrm{Fe}>\mathrm{Al}$ with values $0.96>0.86>0.79>0.64>0.637>0.58>0.47>0.45>0.35>0.32$. The high variation was seen for the heavy metals ( $\mathrm{Pb}, \mathrm{Ni}, \mathrm{Co}, \mathrm{Cu}, \mathrm{Cr}, \mathrm{Zn}, \mathrm{Mn}$, and $\mathrm{Cd}$ ), pointing towards a significant contribution of anthropogenic sources in the study area for these metals. Medium variation was observed for $\mathrm{Al}$ and $\mathrm{Fe}$, which indicates the minimum input of $\mathrm{Al}$ and Fe by anthropogenic sources.

\subsection{Potential ecological risk index}

The potential ecological risk was used to assess the degree of heavy metals pollution in soil, and the results are presented in figures $4 \& 5$. Amongst the studied metals, PERI was calculated for $\mathrm{Cd}, \mathrm{Pb}, \mathrm{Cu}, \mathrm{Ni}, \mathrm{Cr}$, and $\mathrm{Zn}$. The value of PERI was found to be highest for $\mathrm{Cd}$ in all the analyzed samples. Moderate to considerable potential ecological risk (Ei) has been observed in agricultural soil samples collected from national highways, state highways, Yamuna floodplains, and industrial areas, whereas WWI soil samples showed a considerable potential ecological risk (Ei) due to the presence of Cd. The level of ecological risk index (Ri) was high for 75 \% of the soil samples irrigated with wastewater due to the presence of $\mathrm{Cd}, \mathrm{Pb}, \mathrm{Cu}, \mathrm{Ni}, \mathrm{Cr}$, and $\mathrm{Zn}$. 
Pearson correlation analysis was performed between heavy metals, and a close association between heavy metals has been observed (Table 4). A strong positive correlation was observed between $\mathrm{Cd}$, Fe, and Al, which indicates their common source of origin i.e. crustal. Ni showed a positive correlation with $\mathrm{Cr}$, $\mathrm{Zn}$, and $\mathrm{Cu}$, suggesting that the potential source of these metals in agricultural soils is anthropogenic. Pb was significantly and positively correlated with Mn and $\mathrm{Co}$, which intimate their vehicular source of origin. A comparison of principal components analysis (PCA), loading, and the cumulative percentage for varimax normalized matrix and factor scores for different agricultural sites are shown in the Table 5 . There were three components with an eigenvalue greater than 1 after varimax rotation, which indicates the presence of multiple sources of heavy metals in the study area. Results of the PCA and dendrogram analysis suggested the formation of three primary cluster pairs are Ni-Cr-Zn-Cu, Fe-Al-Cd, and Pb-Mn-Co (figure 6). In the Principal component analysis (Table 5), Factor 1 contributed to $34.71 \%$ of total variance with a high loading of $\mathrm{Ni}, \mathrm{Cr}, \mathrm{Zn}$, and $\mathrm{Cu}$ which indicate their common source of origin i.e. industrial. Factor 2 contributed to $23.68 \%$ of total variance with the high loading $\mathrm{Fe}, \mathrm{Al}$, and $\mathrm{Cd}$ suggesting their agricultural and crustal source of origin. Factor 3 contributed to $22.49 \%$ of total variance with the high loading of $\mathrm{Pb}, \mathrm{Mn}$, and $\mathrm{Co}$, suggesting a vehicular source of origin.

\section{Conclusions}

Wastewater irrigated soils had shown the highest level of contamination due to the presence of heavy metals. The significant potential ecological risk has been noticed in nearly all the agricultural soil samples except for the samples collected nearby residential areas. All soil samples were enriched with heavy metals like $\mathrm{Zn}, \mathrm{Cd}, \mathrm{Pb}, \mathrm{Mn}$, and Ni with moderate to a strong level of contamination. The soil samples collected from Kabirpur (Sonipat) area were strongly contaminated with $\mathrm{Cd}, \mathrm{Ni}$, and $\mathrm{Zn}$. Thus we can say that the use of wastewater/ sewage for irrigation has resulted in a high concentration of heavy metals $(\mathrm{Zn}, \mathrm{Ni}, \mathrm{Cu}, \mathrm{Cd}$, and $\mathrm{Cr})$ in the soil samples, and cultivation of vegetables/cereals in such soils may lead to the bioaccumulation of heavy metals in them. $\mathrm{A}$ further study of heavy metals in vegetables grown in this type of area is highly recommended. From the CV and statistical analysis, it may be concluded that anthropogenic sources of heavy metals (metal industries, sewage water, the use of phosphate fertilizers, etc.) in the study area are present. From the results of the present study, it can be concluded that a monitoring plan is necessary to evaluate the levels of metal concentration in agricultural soils of NCR and to develop the proper measures for reducing the concentrations of heavy metals building up in the soils.

\section{Declarations}

\section{Availability of data and materials}

All data generated or analysed during this study are included in this published article.

\section{Competing interests}

The authors declare that they have no competing interests" in this section.

\section{Funding}

No funding has been received for design of the study and collection, analysis, and interpretation of data and in writing the manuscript

\section{Authors' contributions}

Investigation: [Jyoti Rani],

Methodology: [Jyoti Rani and Sudesh Chaudhary],

Formal analysis and investigation: [Jyoti Rani],

Writing - original draft preparation: [Jyoti Rani and Sudesh Chaudhary];

Writing - review and editing: [Jyoti Rani, Sudesh Chaudhary and Tripti Agarwal],

Supervision: [Sudesh Chaudhary and Tripti Agarwal]

All authors read and approved the final manuscript.

\section{References}

1. Sharma RK, Agrawal M, Marshall FM. Heavy metal ( $\mathrm{Cu}, \mathrm{Zn}, \mathrm{Cd}$ and $\mathrm{Pb}$ ) contamination of vegetables in urban India: A case study in Varanasi. Environ Pollut. 2008; 154(2):254-263.

2. Singh A, Sharma RK, Agarwal M, Marshall FM. Risk assessment of heavy metal toxicity through contaminated vegetables from waste water irrigated area of Varanasi, India. IntSocTrophical Ecol. 2010;51(02):375-387.

3. Lente I, Keraita B, Drechsel P, Ofosu-Anim J, Brimah AK. Risk assessment of heavy-metal contamination on vegetables grown in long-term wastewater irrigated urban farming sites in Accra, Ghana. Water Qual Expo Heal. 2012; 4:179-186.

4. E T Puttaih J. Heavy metal contamination in soil under the application of polluted sewage water across Vrishabhavathi River. Internnational J Eng Res Appl. 2012;2(6):1666-1671.

5. Cheng S. Heavy metals in plants and phytoremediation. Environ SciPollut Res. 2003;10(5):335-340. 
6. Poonam Y, Balvinder S, Garg VK, Suman M, Vandana P. Bioaccumulation and health risks of heavy metals associated with consumption of rice grains from croplands in Northern India. Hum Ecol Risk Assess. 2017;23(1):14-27.

7. Rani J, Kaushik CP. Potential of Various Immobilization Matrices in Heavy Metal Ions Removal Using Nostoclinckia beads: A Comparative Study. IOSR J Environ SciToxicol Food Technol. 2014;8(12):31-40.

8. Rajindiran S, Dotaniya ML, Coumar MV, Panwar NR, Saha JK. Heavy metal polluted Soils in India: status and countermeasures. JNKVV Res J. 2015;49(3):320-337.

9. Chaudhary S, Banerjee DK, Kumar N, Yadav S. Assessment of bioavailable metals in the sediments of Yamuna flood plain using two different single extraction procedures. Sustain Environ Res. 2016;26(1):28-32.

10. Rieuwerts JS, Thornton I, Farago ME, Ashmore MR. Factors influencing metal bioavailability in soils: Preliminary investigations for the development of a critical loads approach for metals. ChemSpeciatBioavailab. 1998;10(2):61-75.

11. Achparaki M, Thessalonikeos E, Tsoukali H, et al. Heavy metals toxicity . Aristotle Univ Med J. 2012;39(1):29-34.

12. Map of India. https://www.mapsofindia.com/maps/delhi/delhi-ncr-map.html. Accessed November 9, 2020.

13. State Industrial Profile of Haryana. Ministry of Micro, small and medium enterprises, Karnal, Government of India. 2015. P.1-63.

14. Sharma R, Agrawal M, Marshall F. Heavy metal contamination of soil and vegetables in suburban areas of Varanasi, India. Ecotoxicol Environ Saf. 2007;66(2):258-266.

15. Islam MS, Ahmed MK, Habibullah-Al-Mamun M. Apportionment of heavy metals in soil and vegetables and associated health risks assessment. Stoch Environ Res Risk Assess. 2016;30(1):365-377.

16. Global Soil Laboratory Network. Standard Operating Procedure for Soil Organic Carbon Walkley-Black Method. Vol1.; 2019.

17. Kumar R, Agrawal M, Marshall F, Kumar Sharma R, Agrawal M, Marshall F. Heavy metal contamination of soil and vegetables in suburban areas of Varanasi , India. Ecotoxicol Environ Saf. 2007;66(2):258-266.

18. $\mathrm{Li} \mathrm{H}, \mathrm{Ji} \mathrm{H}$, Shi C, et al. Distribution of heavy metals and metalloids in bulk and particle size fractions of soils from coal-mine brownfield and implications on human health. Chemosphere. 2017;172:505-515.

19. Chen L, Wang G, Wu S, et al. Heavy metals in agricultural soils of the Lihe River watershed, East China: spatial distribution, ecological risk, and pollution source. Int J Environ Res Public Health. 2019;16(2094).

20. Herk A van. Physicochemical parameters in soil and vegetable samples from Gongulon agricultural site, Maiduguri, Borno State, Nigeria. Int $\mathrm{J}$ Chem. 2012;1:21-36.

21. Khaledian Y, Pereira P, Brevik EC, Pundyte N, Paliulis D. The influence of organic carbon and pH on heavy metals, potassium, and magnesium levels in Lithuanian Podzols. L Degrad Dev. 2016;28(1):345-354.

22. Daulta R, Rani J, Yadav A. Effect of sugar mill effluent on physico-chemical properties of soil at Panipat City, India. Int Arch ApplSci Technol. 2014;5(2):612.

23. Geetha S, Byragi Reddy T, Hemalatha KPJ. Physico-chemical analysis of selected agricultural soil samples in KommangiPanchythi, ChintapalliMadal, Visakhapatnam. Int J Inf Res Rev. 2017;04(1):3530-3532.

24. Li G, Lu N, Wei Y, Zhu D. Relationship between Heavy Metal Content in Polluted Soil and Soil Organic Matter and pH in Mining Areas. IOP ConfSer Mater Sci Eng. 2018;394(5):1-7.

25. Garg VK, Yadav P, Mor S, Singh B, Pulhani V. Heavy metals bioconcentration from soil to vegetables and assessment of health risk caused by their ingestion. Biol Trace Elem Res. 2014;157(3):256-265.

26. Punetha D, Tewari G. Investigation on heavy metal content in common grown vegetables from polluted sites of Moradabad district, India. $\mathrm{J}$ Indian ChemSoc 2015;92(1):97-103.

27. Kaushik A, Kansal A, Santosh, Meena, Kumari S, Kaushik CP. Heavy metal contamination of river Yamuna, Haryana, India: Assessment by Metal Enrichment Factor of the Sediments. J Hazard Mater. 2009;164(1):265-270.

28. Bhushan C, Bhardwaj A, Misra SS. State of Pesticide Regulations in India. Centre for Science and Environment, New Delhi. 2013. p.1-72.

29. Howe PD, Malcolm HM, Dobson S. Manganese and Its Compounds: Environmental Aspects. World Health Organization. 2004. P. 1-63.

30. Craig DB, Mccluhan TK. United States Patent (19). 1990;(4941914):1-12.

31. Bharti PK, Kumar P, Singh V. Impact of industrial effluents on ground water and soil quality in the vicinity of industrial area of Panipat city, India. J Appl Nat Sci. 2013;5(1):132-136.

32. Singh S, Raju NJ, Nazneen S. Environmental risk of heavy metal pollution and contamination sources using multivariate analysis in the soils of Varanasi environs, India. Environ Monit Assess. 2015;187(6):1-12.

33. Tian K, Huang B, Xing Z, Hu W. Geochemical baseline establishment and ecological risk evaluation of heavy metals in greenhouse soils from Dongtai, China. Ecol Indic. 2017;72:510-520.

34. Iyaka YA. Nickel in soils: A review of its distribution and impacts. Sci Res Essays. 2011;6(33):6774-6777.

35. Verma P, Agrawal M, Sagar R. Assessment of potential health risks due to heavy metals through vegetable consumption in a tropical area irrigated by treated wastewater. Environ SystDecis. 2015;35(3):375-388.

36. Bhagure GR, Mirgane SR. Heavy metal concentrations in groundwaters and soils of Thane Region of Maharashtra, India. Environ Monit Assess. 2011;173(1-4):643-652. 
37. Proshad R IM, T K, MS B, et al. Contamination of Heavy Metals in Agricultural Soils: Ecological and Health Risk Assessment. SF J Nanochemistry Nanotechnol. 2019;2(1):1012.

38. Rao PS, Thomas T, Hasan A, David A. Determination of Heavy Metals Contamination in Soil and Vegetable Samples from Jagdalpur, Chhattisgarh State, India. Int J CurrMicrobiol App Sci. 2017;6(8):2909-2914.

39. Chaoua S, Boussaa S, El Gharmali A, Boumezzough A. Impact of irrigation with wastewater on accumulation of heavy metals in soil and crops in the region of Marrakech in Morocco. J Saudi SocAgric Sci. 2019;18(4):429-436.

40. Debnath B, Singh WS, Manna K. Sources and toxicological effects of lead on human health. Indian J Med Spec. 2019;10:66-71.

41. Wuana R, Okieimen FE. Heavy Metals in Contaminated Soils: A Review of Sources, Chemistry, Risks and Best Available Strategies for Remediation. ISRN Ecol. 2011:1-20.

42. Niu S, Gao L, Wang X. Characterization of contamination levels of heavy metals in agricultural soils using geochemical baseline concentrations. J Soils Sediments. 2019;19:1697-1707.

43. Vanita C, Piar C, Avinash N, Kaur KJ, B PY. Evaluation of Heavy Metals Contamination and its Genotoxicity in Agricultural Soil of Amritsar , Punjab , India. Int J Res ChemEnvrionment. 2014;4(4):20-28.

44. Murti CRK. The Cycling of Arsenic, Cadmium, Lead and Mercury in India. In: Thomas C. Hutchinson KMM, ed. Lead, Mercury, Cadmium and Arsenic in the Environment. Wiley-Blackwell; 1987:315-333.

45. Roberts TL. Cadmium and phosphorous fertilizers: The issues and the science. Procedia Eng. 2014;83:52-59.

46. Hu W, Huang B, Tian K, Holm PE, Zhang Y. Heavy metals in intensive greenhouse vegetable production systems along Yellow Sea of China: Levels, transfer and health risk. Chemosphere. 2017;167:82-90.

47. Singh S, Kumar M. Heavy metal load of soil, water and vegetables in peri-urban Delhi. Environ Monit Assess. 2006;120(1-3):79-91.

48. Zhang H, Huang B, Dong L, Hu W, Akhtar MS, Qu M. Accumulation, sources and health risks of trace metals in elevated geochemical background soils used for greenhouse vegetable production in southwestern China. Ecotoxicol Environ Saf. 2017;137:233-239.

49. Kumar V, Sharma A, Kaur P, et al. Pollution assessment of heavy metals in soils of India and ecological risk assessment: A state-of-the-art. Chemosphere. 2019;216:449-462.

50. Giri S, Singh AK. Ecological and human health risk assessment of agricultural soils based on heavy metals in mining areas of Singhbhum copper belt, India. Hum Ecol Risk Assess. 2017;23(5):1008-1027.

51. US Environmental Protection Agency. US EPA Ecological Soil Screening Level for Aluminium; 2014. p. 1-1.

\section{Tables}

Table 1 Classification of CF

\begin{tabular}{ccccccc}
\hline Level of contamination & uncontaminated & Slight & moderate & Considerable & Strong & Very strong \\
\hline CF (Individual Metal) & $\leq 0$ & $0<\mathrm{CF} \leq 1$ & $1<\mathrm{CF} \leq 3$ & $3<\mathrm{CF} \leq 5$ & $5<\mathrm{CF} \leq 6$ & $\mathrm{CF}>6$ \\
\hline
\end{tabular}

Table $2 \quad$ Classification of RI and $\mathrm{E}_{\mathrm{i}}$

\begin{tabular}{cccccc}
\hline Risk (RI) & Low & Moderate & Considerable & High & very high \\
\hline RI & $\leq 150$ & $150<\mathrm{RI} \leq 300$ & $300<\mathrm{RI} \leq 600$ & -- & $>600$ \\
$\mathrm{E}_{\mathrm{i}}$ & $<40$ & $40-80$ & $80-160$ & $160-320$ & $\geq 320$ \\
\hline
\end{tabular}

Table 3 Heavy metals concentration in the agricultural soil samples collected from NCR, India 


\begin{tabular}{|c|c|c|c|c|c|c|c|c|}
\hline \multicolumn{9}{|c|}{ Heavy metals (mg kg${ }^{-1}$} \\
\hline $\begin{array}{c}\text { Site } \\
\text { description }\end{array}$ & $\mathrm{Al}$ & $\mathrm{Cd}$ & Co & $\mathrm{Cr}$ & $\mathrm{Cu}$ & $\mathrm{Fe}$ & $\mathrm{Mn}$ & $\mathrm{Ni}$ \\
\hline Industrial & $\begin{array}{c}14765.79 \pm 4170.35 \\
(7940-25805.06)\end{array}$ & $\begin{array}{l}0.98 \pm 0.38 \\
(0.20- \\
1.92)\end{array}$ & $\begin{array}{l}1.99 \pm 1.31 \\
(0.1-5.03)\end{array}$ & $\begin{array}{l}24.01 \pm 9.57 \\
(9.65-46.15)\end{array}$ & $\begin{array}{l}18.21 \pm \\
9.16(6.55- \\
39.80)\end{array}$ & $\begin{array}{c}15330.79 \pm 4038.94 \\
(8560.02- \\
27270.01)\end{array}$ & $\begin{array}{l}220.63 \pm 76.50 \\
(73.80-334.90)\end{array}$ & $\begin{array}{c}40 \pm 10.07 \\
(26.32-68.41\end{array}$ \\
\hline $\begin{array}{l}\text { National } \\
\text { Highways }\end{array}$ & $\begin{array}{c}15831.02 \pm 4522.01 \\
(11895-27209.99)\end{array}$ & $\begin{array}{l}1.07 \pm 0.27 \\
(0.72- \\
1.81)\end{array}$ & $\begin{array}{l}2.3 \pm 1.19 \\
\quad(0.62- \\
4.32)\end{array}$ & $\begin{array}{l}49.28 \pm 13.82 \\
(23.25-71.73)\end{array}$ & $\begin{array}{c}34.11 \pm 6.58 \\
(26.9- \\
52.31)\end{array}$ & $\begin{array}{c}17063.15 \pm 5479.8 \\
(8538.37- \\
32650.23)\end{array}$ & $\begin{array}{l}312.43 \pm 149.43 \\
(215.7-721.58)\end{array}$ & $\begin{array}{c}23.9 \pm 6.62 \\
(17.81-40.9 \varepsilon\end{array}$ \\
\hline $\begin{array}{l}\text { State } \\
\text { Highways }\end{array}$ & $\begin{array}{c}17717.89 \pm \\
3151.19(6743.54- \\
15463.5)\end{array}$ & $\begin{array}{l}1.5 \pm 0.21 \\
(0.61- \\
1.23)\end{array}$ & $\begin{array}{l}1.86 \pm 1.69 \\
(0-6.22)\end{array}$ & $\begin{array}{c}75.62 \pm 6.36 \\
(33.42-57.19)\end{array}$ & $\begin{array}{c}40.36 \pm \\
10.16 \\
(13.43- \\
44.62)\end{array}$ & $\begin{array}{c}18317.97 \pm 1670.92 \\
(8221.55-13962)\end{array}$ & $\begin{array}{c}727.64 \pm 124.99 \\
(297-735.72)\end{array}$ & $\begin{array}{r}62.53 \pm 7.56 \\
(26.85-57.7 \subseteq\end{array}$ \\
\hline $\begin{array}{l}\text { Waste } \\
\text { water } \\
\text { Irrigated }\end{array}$ & $\begin{array}{c}16619.38 \pm 675.37 \\
(15815.48- \\
17435.53)\end{array}$ & $\begin{array}{l}1.54 \pm 0.38 \\
\quad(1.05- \\
1.96)\end{array}$ & $\begin{array}{l}0.79 \pm 0.15 \\
\quad(0.61- \\
0.96)\end{array}$ & $\begin{array}{c}102.32 \pm 18.61 \\
(82.13- \\
127.21)\end{array}$ & $\begin{array}{l}66.6 \pm 4.8 \\
(60.32- \\
70.43)\end{array}$ & $\begin{array}{c}21279.06 \pm 579.41 \\
(20594.89- \\
21890.5)\end{array}$ & $\begin{array}{c}319.77 \pm 31 \\
(285.45- \\
354.48)\end{array}$ & $\begin{array}{c}157.15 \pm 28.7 \\
(122.3- \\
192.63)\end{array}$ \\
\hline $\begin{array}{l}\text { Yamuna } \\
\text { floodplain }\end{array}$ & $\begin{array}{c}15119.8 \pm 3273.97 \\
(10850.18- \\
20215.5)\end{array}$ & $\begin{array}{l}1.23 \pm 0.29 \\
(0.82- \\
1.72)\end{array}$ & $\begin{array}{l}3.33 \pm 1.76 \\
(1.41- \\
7.82-)\end{array}$ & $\begin{array}{c}21.85 \pm 3.55 \\
(16.91-27.75)\end{array}$ & $\begin{array}{c}15.75 \pm 3.77 \\
(9.91- \\
22.16)\end{array}$ & $\begin{array}{c}20679.23 \pm 4282.88 \\
(12610.33- \\
26640.2)\end{array}$ & $\begin{array}{l}295.66 \pm 58.95 \\
(182.11- \\
375.55)\end{array}$ & $\begin{array}{c}21.77 \pm 4.1 \\
(13.61-27.74\end{array}$ \\
\hline Residential & $\begin{array}{c}9961.94 \pm 3122.45 \\
(5631-18759.83)\end{array}$ & $\begin{array}{l}0.36 \pm 0.12 \\
(0.15- \\
0.55)\end{array}$ & $\begin{array}{l}0.61 \pm 0.38 \\
\quad(0.13- \\
1.25)\end{array}$ & $\begin{array}{c}16.94 \pm 5.27 \\
(9.8-27.4)\end{array}$ & $\begin{array}{c}9.85 \pm \\
3.49(5.12- \\
19.32)\end{array}$ & $\begin{array}{c}11478.79 \pm \\
3496.46(6640.09- \\
20990.19)\end{array}$ & $\begin{array}{c}165.06 \pm 51.99 \\
(96.16-288.8)\end{array}$ & $\begin{array}{l}14.19 \pm 4.59 \\
(7.63-26.03\end{array}$ \\
\hline $\begin{array}{c}\text { Indian } \\
\text { natural soil } \\
\text { Background } \\
{[49-51]}\end{array}$ & -- & -- & 15.2 & 114 & 56.5 & 32015 & 209 & 27.7 \\
\hline
\end{tabular}

Table $4 \quad$ Pearson's correlation matrix

\begin{tabular}{ccccccccccc}
\hline & $\mathrm{Al}$ & $\mathrm{Cd}$ & $\mathrm{Co}$ & $\mathrm{Cr}$ & $\mathrm{Cu}$ & $\mathrm{Fe}$ & $\mathrm{Mn}$ & $\mathrm{Ni}$ & $\mathrm{Pb}$ & $\mathrm{Zn}$ \\
\hline $\mathrm{Al}$ & 1 & & & & & & & & & \\
$\mathrm{Cd}$ & $.631^{* *}$ & 1 & & & & & & & \\
$\mathrm{Co}$ & $.442^{* *}$ & $.521^{* *}$ & 1 & & & & & & \\
$\mathrm{Cr}$ & $.433^{* *}$ & $.497^{* *}$ & .050 & 1 & & & & & \\
$\mathrm{Cu}$ & $.433^{* *}$ & $.640^{* *}$ & $.244^{*}$ & $.854^{* *}$ & 1 & & & & & \\
$\mathrm{Fe}$ & $.679^{* *}$ & $.641^{* *}$ & $.275^{*}$ & $.328^{* *}$ & $.341^{* *}$ & 1 & & & & \\
$\mathrm{Mn}$ & $.227^{*}$ & $.457^{* *}$ & $.419^{* *}$ & $.451^{* *}$ & $.498^{* *}$ & .160 & 1 & & & \\
$\mathrm{Ni}$ & $.321^{* *}$ & $.477^{* *}$ & -.028 & $.764^{* *}$ & $.705^{* *}$ & $.331 * *$ & .214 & 1 & & \\
$\mathrm{~Pb}$ & .160 & $.403^{* *}$ & $.485^{* *}$ & $.305^{* *}$ & $.500^{* *}$ & .102 & $.573^{* *}$ & -.024 & 1 & \\
$\mathrm{Zn}$ & $.281^{* *}$ & $.558^{* *}$ & .191 & $.747^{* *}$ & $.787^{* *}$ & .151 & $.495^{* *}$ & $.770^{* *}$ & $.262^{*}$ & 1 \\
\hline
\end{tabular}

**. Correlation is significant at the 0.01 level (2-tailed).

*. Correlation is significant at the 0.05 level (2-tailed).

Table 5 PCA analysis (Rotated component matrix): Varimax with Kaiser Normalization.

\begin{tabular}{cccc}
\hline Heavy metals & Factor-1 & Factor-2 & Factor-3 \\
\hline $\mathrm{Al}$ & .210 & $\mathbf{. 8 5 8}$ & .130 \\
$\mathrm{Cd}$ & .420 & $\mathbf{6 8 3}$ & .400 \\
$\mathrm{Co}$ & -.131 & .465 & .707 \\
$\mathrm{Cr}$ & $\mathbf{. 8 9 0}$ & .202 & .153 \\
$\mathrm{Cu}$ &. $\mathbf{8 3 0}$ & .241 & .366 \\
$\mathrm{Fe}$ & .154 & $\mathbf{. 8 8 8}$ & -.009 \\
$\mathrm{Mn}$ & .369 & .045 & $\mathbf{. 7 4 9}$ \\
$\mathrm{Ni}$ & $\mathbf{. 8 9 7}$ & .231 & -.156 \\
$\mathrm{~Pb}$ & .139 & .022 & $\mathbf{. 8 7 5}$ \\
$\mathrm{Zn}$ & $\mathbf{. 8 7 7}$ & .078 & .251 \\
\hline Eigen Value & 3.471 & 2.368 & 2.249 \\
\hline \% of Variance & 34.711 & 23.679 & 22.49 \\
\hline Cumulative \% & 34.711 & 58.389 & 80.879 \\
\hline
\end{tabular}

\section{Figures}




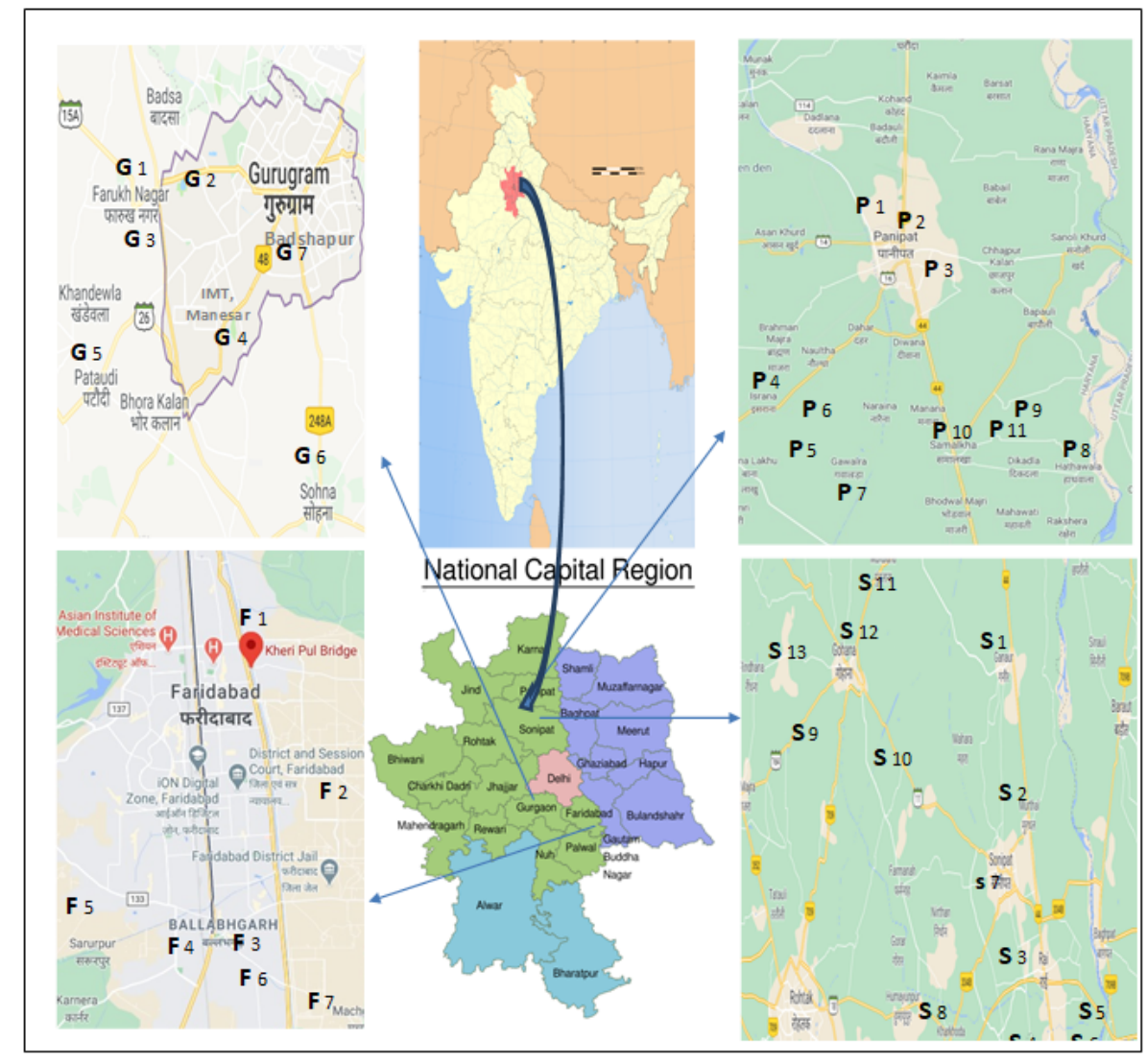

Figure 1

Map of the study area. Note: The designations employed and the presentation of the material on this map do not imply the expression of any opinion whatsoever on the part of Research Square concerning the legal status of any country, territory, city or area or of its authorities, or concerning the delimitation of its frontiers or boundaries. This map has been provided by the authors. 


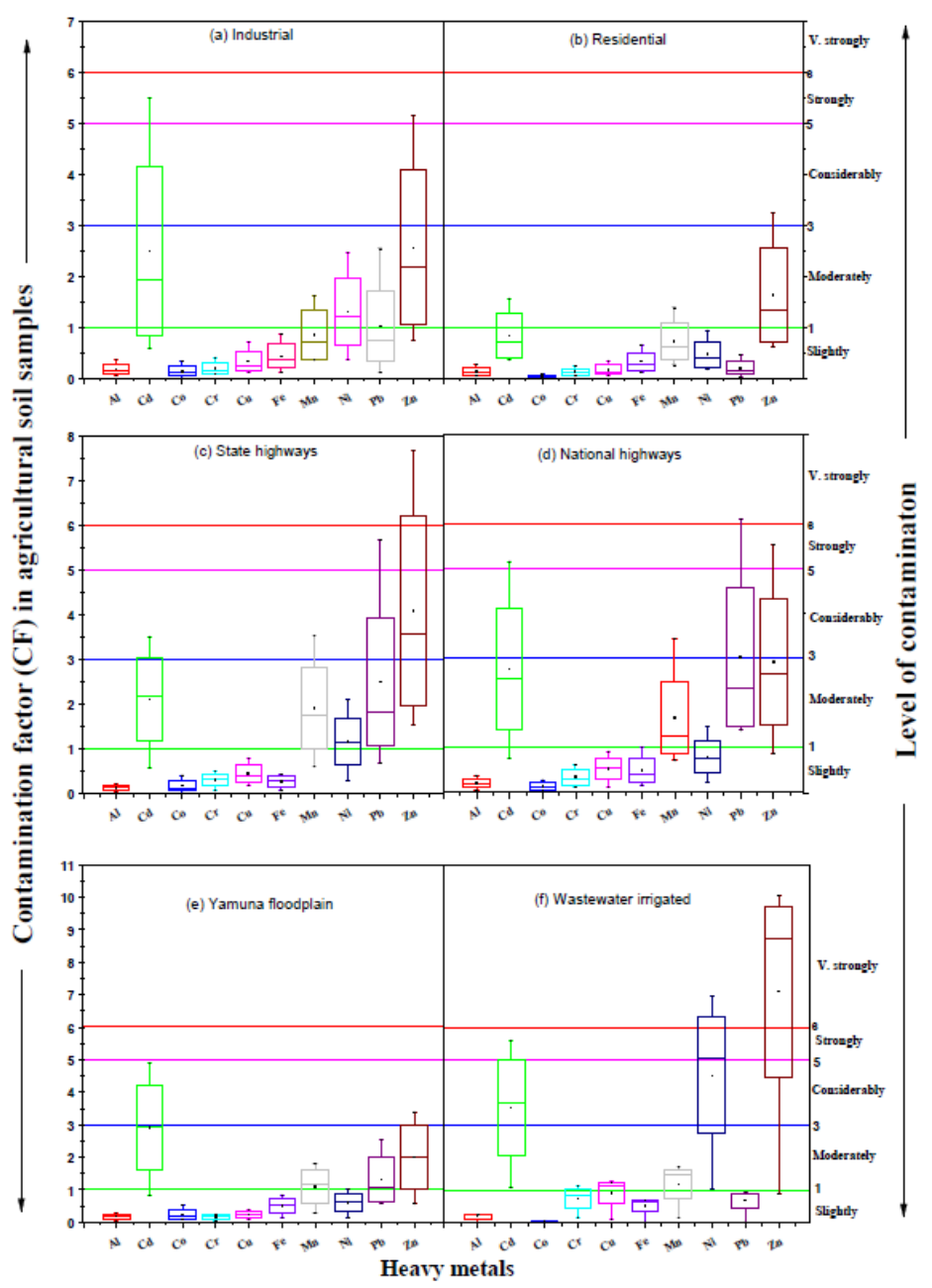

Figure 2

Factor for different heavy metals concentrations in agricultural soil samples 


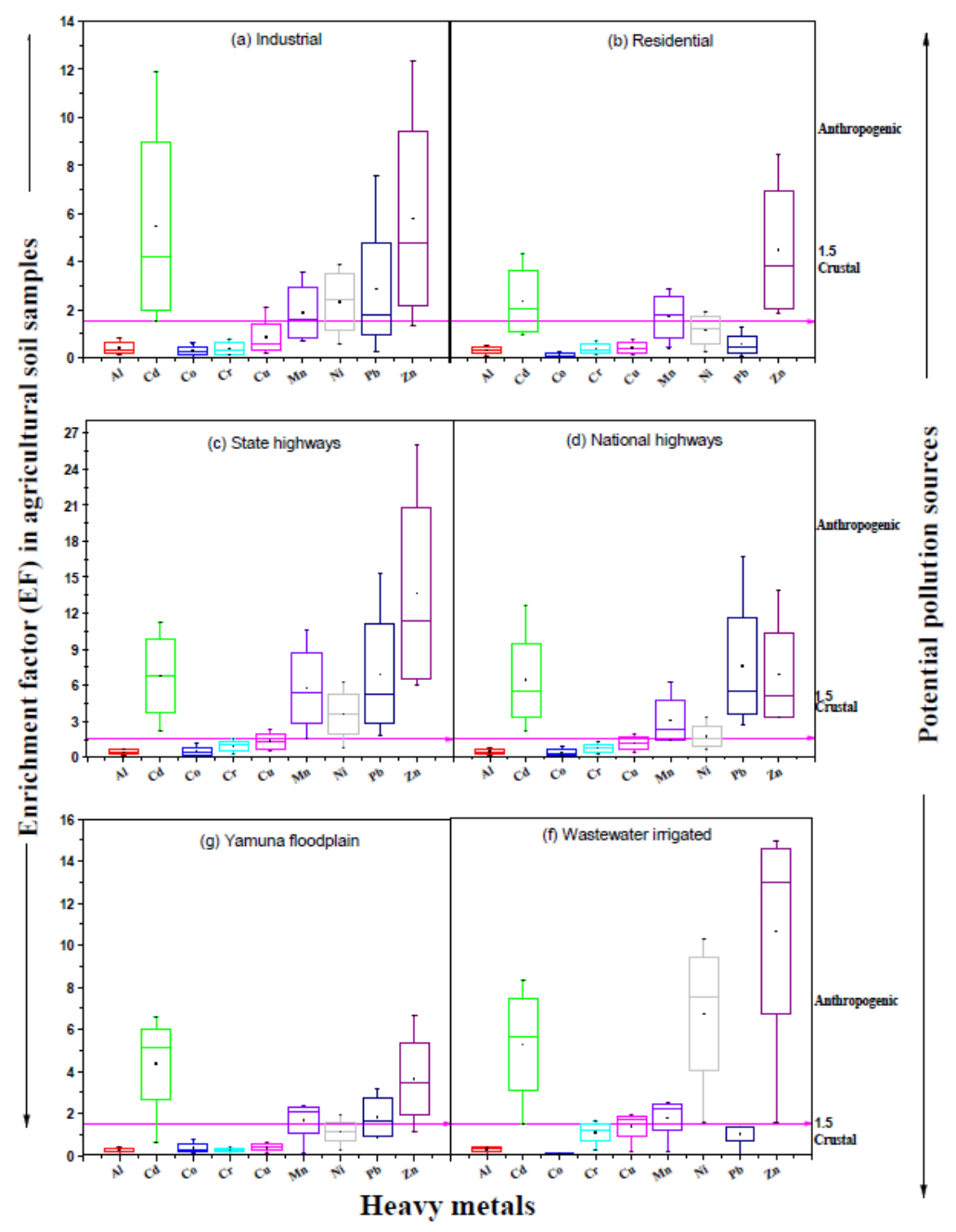

Figure 3

Enrichment Factor for different heavy metals in agricultural soil samples 


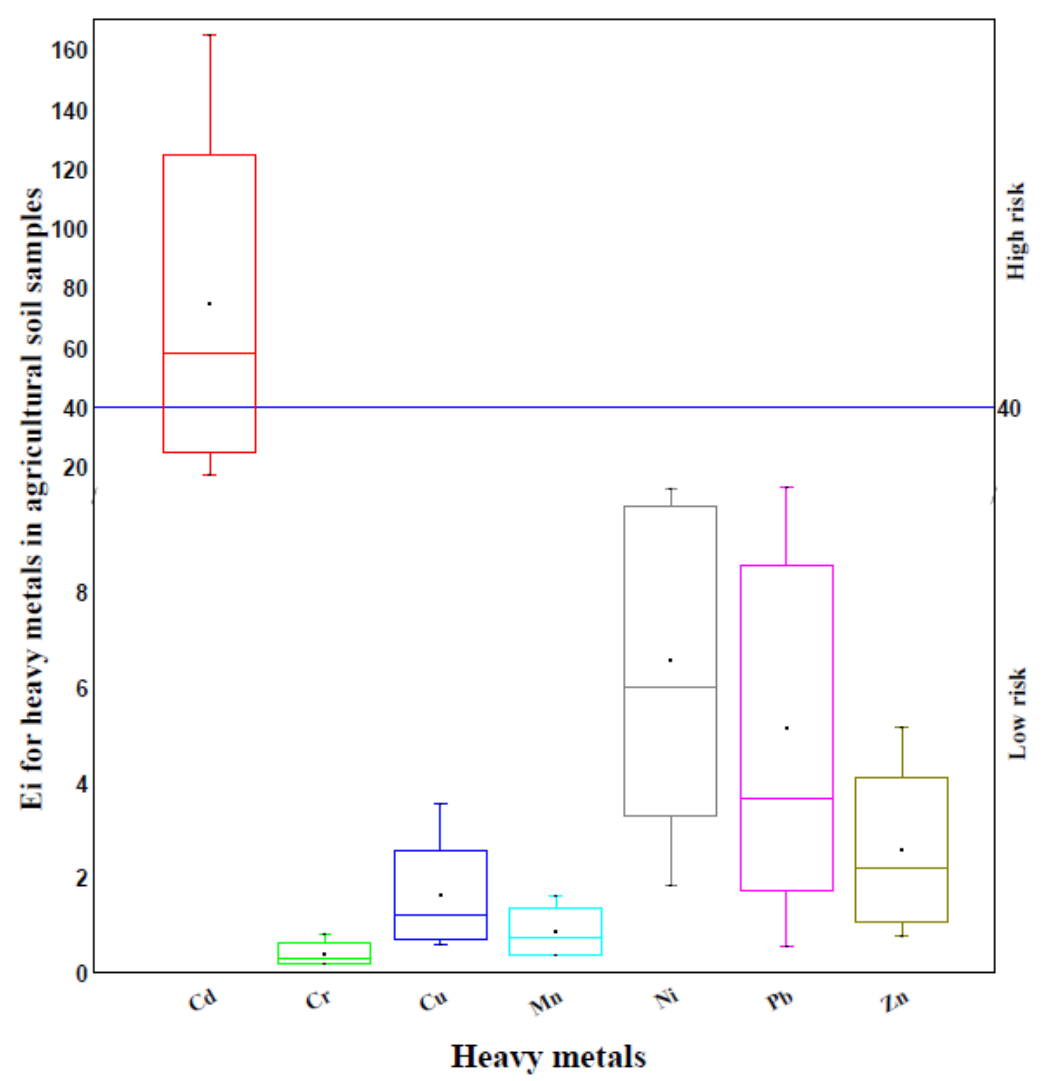

Figure 4

Ecological risk for different heavy metals concentrations in agricultural soil samples

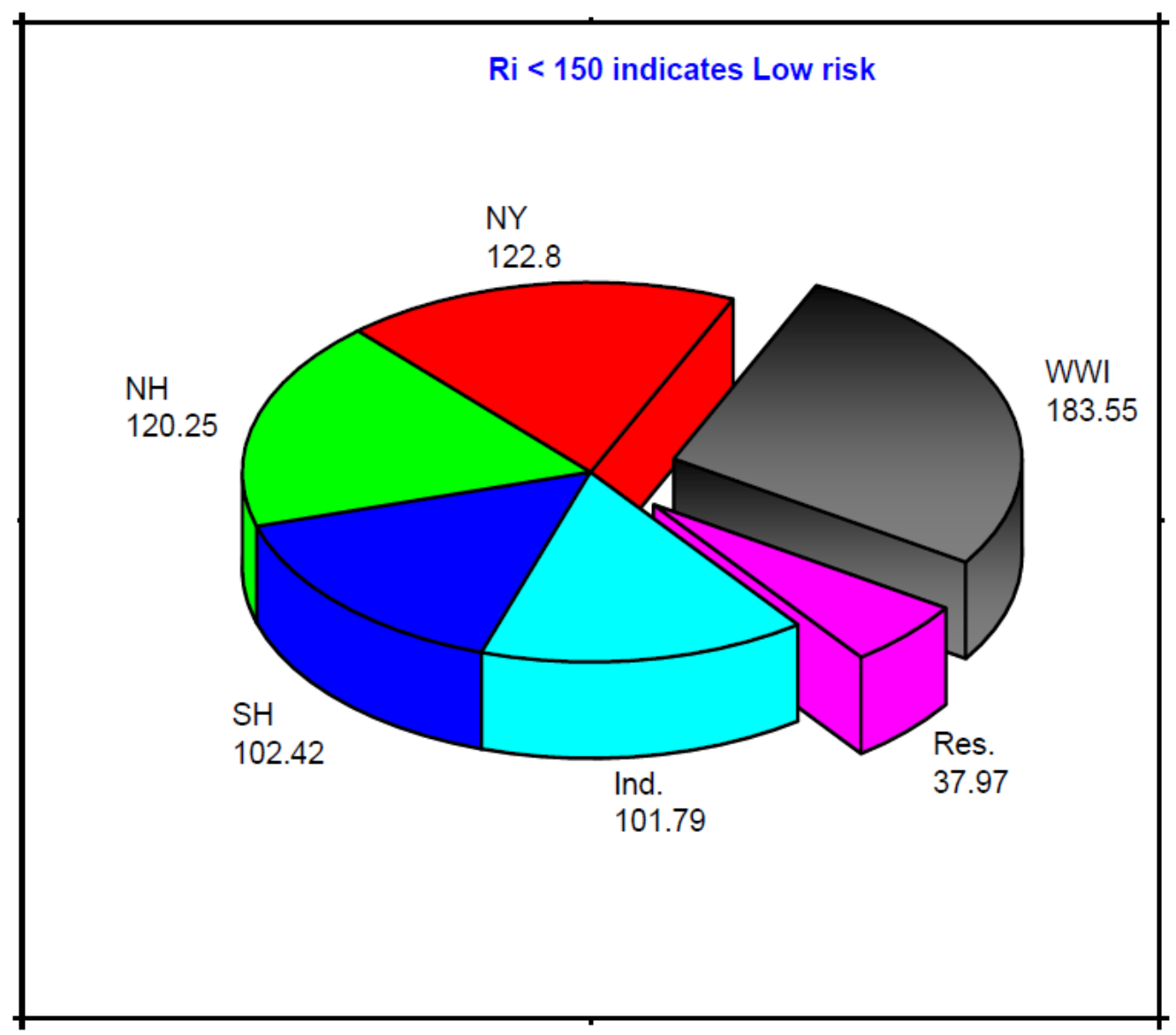

Page $13 / 14$ 
Figure 5

Cumulative potential of ecological risk at different sites.

Component Plot in Rotated Space

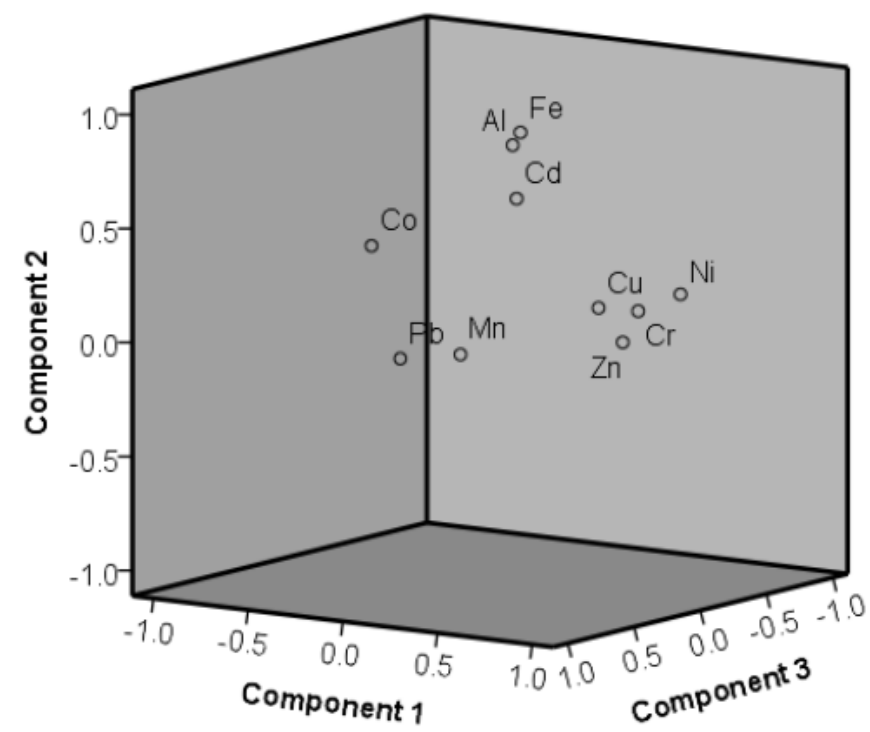

Figure 6

Dendrogram analysis showing the formation of three primary cluster pairs. 